\title{
Design of Flettner Rotor in Container Carrier 4000 DWT with CFD
}

\author{
Irfan Syarif Arief ${ }^{1}$, Agoes Santoso ${ }^{2}$, Abdullah Azzam ${ }^{3}$
}

\begin{abstract}
Flettner rotor is a technology that utilizes the natural wind to help the oncoming vessel. The working principle of the flettner rotor corresponds to the theory of magnus effect, in which the force arises due to the difference in pressure between the two sides of the flettner rotor. In this research the simulated flettner rotor has a diameter of 3 meters with a height of 18 meters. Simulations were performed 16 times with variations performed on rotation of rotor $(0,100,300$, and $500 \mathrm{rpm})$ and wind speed $(5,10,15$, and $20 \mathrm{knots})$. Flettner rotor analysis is done by computational fluid dynamic method. CFD results state that the largest coefficient lift value is on the flettner rotor with rotation $500 \mathrm{rpm}$ with wind speed 20 knots that is equal to 91,13 . While in its use of 4000 DWT container vessel, flettner rotor is more work at the speed of vessel 10 knot with rotation speed of flettner rotor $500 \mathrm{rpm}$ and wind speed $5 \mathrm{knot}$ that is equal to $17,438 \%$ from force that must be expended to move ship.
\end{abstract}

Keywords - flettner rotor, magnus effect, CFD, Numeca

\section{INTRODUCTION}

$\mathrm{S}$ ince the first invention of the steam engine by James

Watt, petroleum has been the most widely used energy source to date. According to British Petroleum in 2015 world oil use has reached 1.9 million barrels per day, where the United States is the largest consumptive country compared to other countries. This may continue to increase given the increasing use of motor vehicles continue to increase significantly. The non-renewable nature of petroleum makes petroleum reserves estimated to be exhausted within 70 years from now [1].

So is the case with ships, fuel oil becomes the number one choice as a source of energy for a ship at this time. Although oil prices are currently at the lowest level since 2014, alternative energy continues to be developed in anticipation of the depletion of petroleum reserves in the world.

Alternative energy must be prepared immediately to anticipate the depletion of petroleum reserves. One alternative energy that has been applied to the shipping industry is the utilization of wind as a source of energy through the media flettner rotor.

Flettner rotor is a cylinder that stands vertically on the ship's body. The cylinders rotate on their axis so as to utilize the blowing wind to be an additional thrust force using the principle of magnus effect. If the fuel on board serves as an energy source to drive the main engine or auxiliary engine, the fuel consumption can be reduced due to the additional thrust force generated by the flettner rotor. Although the technology that has evolved at this time has not enabled a flettner rotor to be a single

${ }^{1}$ Irfan Syarif Arief, Department of Marine Engineering, Institut Teknologi Sepuluh Nopember, Surabaya, 60111, Indonesia.@.its.ac.id

${ }^{2}$ Agoes Santoso, Department of Marine Engineering, Institut Teknologi Sepuluh Nopember, Surabaya, 60111, Indonesia.@.its.ac.id

${ }^{3}$ Abdullah Azzam, Department of Marine Engineering, Institut Teknologi Sepuluh Nopember, Surabaya, 60111, Indonesia. abdullahazzam48@gmail.com energy source, but at least it can reduce fuel consumption and exhaust emissions [2].

\section{A. Flettner Rotor}

Flettner rotor is a cylinder that stands perpendicular to the body of the ship and rotates according to its axes using the help of an electric motor. Flettner rotor was invented by a German inventor named Anton Flettner in the early 1920s. Anton has developed his rotor concept to help ship movements utilize magnus effects, and built two successful examples even though at the time his ideas were not taken by others $[1,3]$.

The magnus effect itself can be found in everyday life as in some sports, where the movement of the ball that is thrown by rotating on its axis will produce a different movement when compared with ordinary throwing ball. Today some parties have revived the concept of the rotor flettner, and in the opinion of some, offer the most effective way to utilize wind as an additional thrust energy.

Flettner rotors need space on the deck and it is possible to increase the overall height of the vessel. In addition, the flettner rotor also provides complicated ship installation, depending on the ship's operational objectives. So in its application requires further consideration when going to use the rotor flettner.

The rotor is driven by an electric motor which then makes the rotor rotate according to its axis. Then the wind that blows through the rotor will experience a pressure difference between the two sides which causes the ship to get an additional thrust force, where the thrust will arise perpendicular to the direction of the coming wind. This is in line with the principle of "Magnus effect".

\section{B. Magnus Effect}

The magnus effect is a force acting on a rotating object in a moving air stream, which is perpendicular to the airflow. The magnus effect is generated when the rotating cylinder produces a fluid pressure difference. The magnus effect was put forward by the German physicist Heinrich Gustav Magnus in 1852 [4]. 
It occurs in a ball-shaped object or cylinder that moves at a certain speed and in a state of rotation on its axis at a certain angular velocity. If the conditions are different, just as the non-cylindrical shape of the object and the ball or the object does not rotate on its axis, then the magnus effect will not be created. What happens is the movement of the object due to a given thrust force without any additional thrust of the magnus effect, see figure 1 .

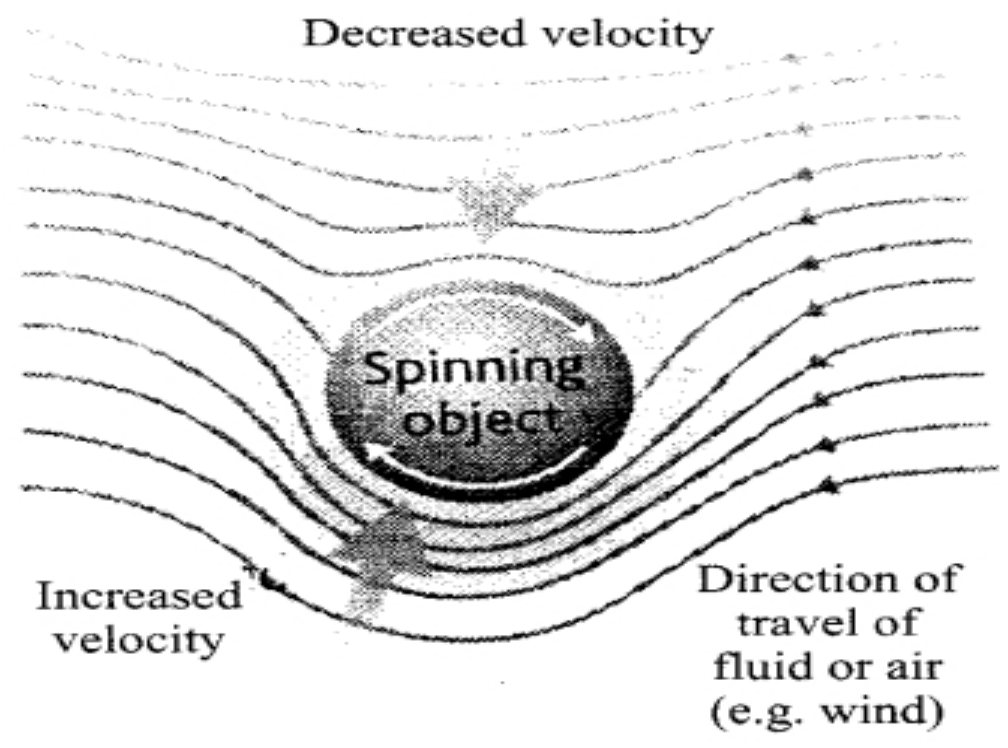

Figure 1. Magnus Effect

As in everyday life the magnus effect can be found in sports activities that use the ball as its object. For example in football when in a free kick, the footballer can take advantage of the wind inside the stadium by kicking the ball in such a way that the ball spins on its axis, thus triggering a magnus effect that makes the direction and velocity of the ball different than it should be.

The idea of making the flettner rotor crossed in 1920 when Anton Flettner tried to find a better way of improving the display on the ship. So Anton Flettner tested a rigid metal structure to optimize sailing aerodynamics. While this test went on he found a quantitative study of the magnus effect on a rotating cylinder. So from here created a flettner rotor that utilizes the magnus effect [5].

\section{Computational Fluid Dynamic}

Computational fluid dynamic is a calculation method with a control of dimensions, area, and volume by utilizing computer computational help to perform calculations on each of the dividing elements. With flow CFD method and heat transfer from various fluids can be simulated on the form / geometry complex. Pressure distribution, flow velocity, mass flow rate, temperature distribution, and fluid flow pattern can be known at each point contained in the analyzed system[4,6].

The CFD method helps the engineer to simulate a product, so it does not take time and high costs. The CFD method has a high degree of accuracy so that the results obtained from the CFD method will not be much different if applied in real terms.

Here are the steps that must be done in doing CFD : 1) Preprocessor
At this stage, defining domains and boundary conditions are used. In addition, the object to be analyzed is also done meshing or division of the number of grids.

2) Processor

Then at the processor stage is the calculation of input data with the equations involved.

3) Postprocessor

And final stage post processor is the result of the calculation.

\section{METHOD}

Modeling is done by making two main areas, first, the cylinder field, where the cylinder will become the rotor flettner which is then calculate the value of force. Then the second is the beam field, the field is useful as fluid medium or fluid flow.

Then the two fields are defined boundary condition, which determines the fluid input, fluid output, solid plane, and external field.

If it has been done then it can be continued with the meshing process. Because of the uncomplicated shape of the flettner rotor or just a cylinder, the determination of the meshing density does not need to be too high. Because if made high density then consequently the process of running or simulation takes longer with results that are not much different if made with a simple density level [7].

Then input parameters, where variations of RPM flettner rotor and wind speed can be performed. In addition, other values can also be included, among others, include 
the type of fluid, flow type, and so forth. In this simulation the blowing wind is assumed to blow at 90 degrees from the direction of the ship's motion.

After all the above steps done, then the next can be done running process. Running process is done 16 times including running condition where the rotor does not rotate or RPM 0.

A flettner rotor can provide an elevated elevation or thrust force due to pressure differentials on both sides of the flettner rotor. Therefore from the simulation results on the difference in pressure picture calculation of pressure values on both sides of the flettner rotor, which then can be taken the value of his force with the following formula :

$$
\begin{aligned}
& F L_{1}=F_{1} x A_{1} \\
& F l_{2}=P_{2} x A_{2} \\
& \mathrm{~A}=1 / 2 \times \rho \times \mathrm{d} \times \mathrm{t} \\
& F\left[=F L_{1}-F L_{2}\right.
\end{aligned}
$$

$F r_{2}=$ Force lift in low pressure side

$$
\mathrm{A} \quad=\text { Area of Flettner Rotor }
$$

Then the above Force Lift value is used to find the value of Coefficient Lift with the formula that has been mentioned previously as follows.

$$
C_{i}=\frac{F}{0,5 x \rho x A x V a^{2}}
$$

The above calculation applies to the flettner rotor that produces the force in accordance with the direction of the motion of the ship.

To know the magnitude of the angle that form the direction of the force is produced by doing the analysis on the simulation results of the pressure distribution. Where the resulting force will lead to the rotor side with high pressure to low pressure. Following an effective angle analysis for the wind direction of the velocity of the vessel, see figure 2 and table 1 [8].

Where :

$\mathrm{Fl} \quad=$ Force lift flettner rotor $\bar{F} L_{1}$

$F \Sigma_{1}=$ Force lift in high pressure side

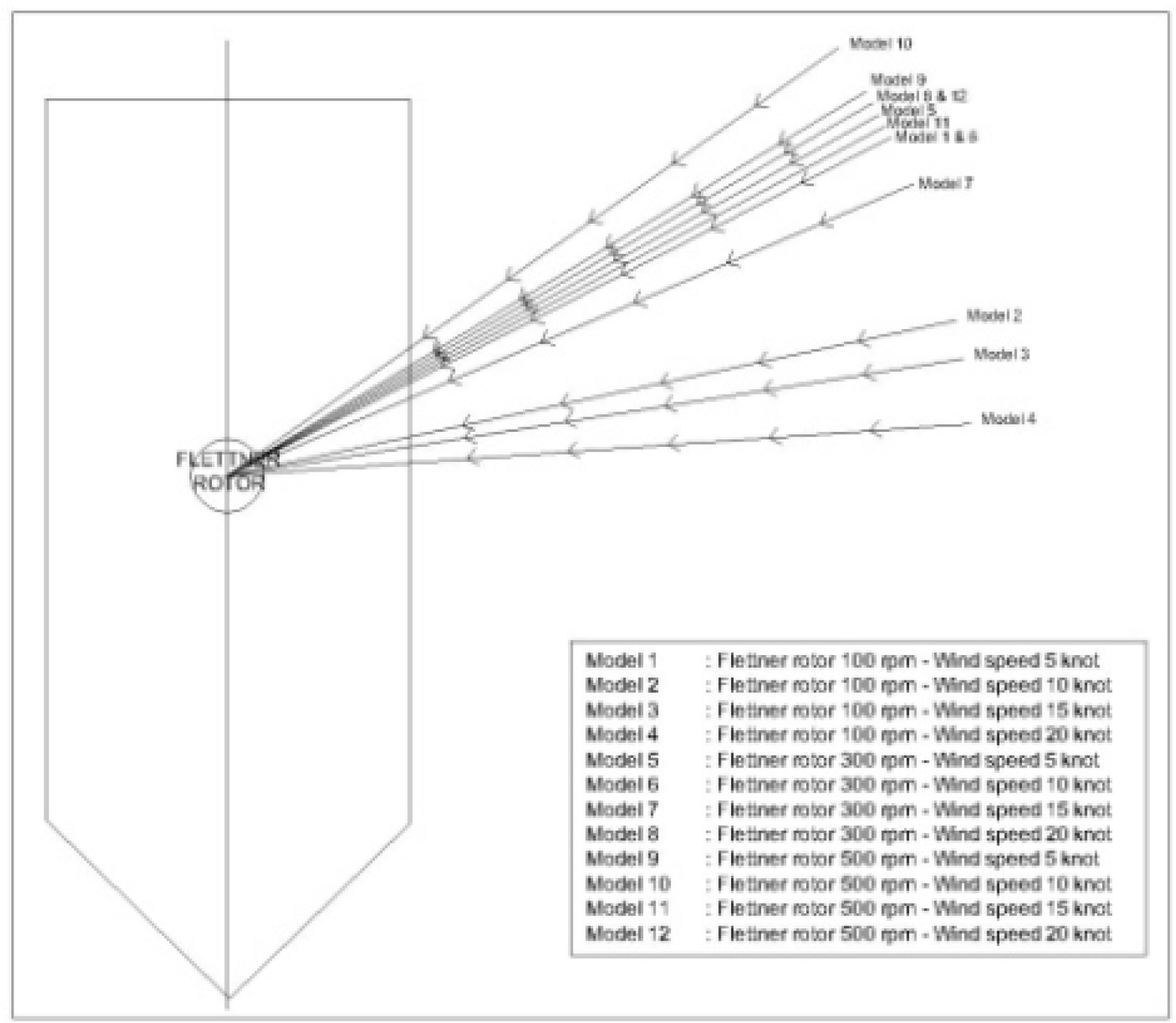

Figure 2. Effective angle of wind for oncoming vessels 
TABLE 1.

EFFECTIVE ANGLE OF WIND FOR ONCOMING VESSELS

\begin{tabular}{cccc}
\hline No. & RPM Rotor & $\begin{array}{c}\text { Speed of Wind } \\
(\mathrm{m} / \mathrm{s})\end{array}$ & Angle of Wind \\
\hline 1 & 100 & 5 & $69^{\mathrm{b}}$ \\
2 & 100 & 10 & $70^{\mathrm{b}}$ \\
3 & 100 & 15 & $81^{\mathrm{b}}$ \\
4 & 100 & 20 & $66^{\mathrm{b}}$ \\
5 & 300 & 5 & $60^{\mathrm{b}}$ \\
6 & 300 & 10 & $69^{\mathrm{b}}$ \\
7 & 300 & 15 & $67^{\mathrm{b}}$ \\
8 & 300 & 20 & $61^{\mathrm{b}}$ \\
9 & 500 & 5 & $59^{\circ}$ \\
10 & 500 & 10 & $55^{\mathrm{b}}$ \\
11 & 500 & 15 & $62^{\mathrm{b}}$ \\
12 & 500 & 20 & $61^{\mathrm{b}}$ \\
\hline
\end{tabular}

The 4000 DWT container ship model to be used as a comparison is "Sakura". Where the container ship has the following dimensions :
Lwl : $103.9 \mathrm{~m}$
Beam : $17.8 \mathrm{~m}$
Draft : $8.5 \mathrm{~m}$

Speed : 16.2 knot

To obtain the value of the thrust effect that produced by the flettner rotor on the container vessel, first the detainee value of the Sakura vessel with Maxsurf software. To facilitate the circulation of the resistance then taken assuming the value of coefficient block worth 0.7 .
Based on the result in maxsurf software it is known that the ship's resistance at the speed of 16.2 knots is worth $875,3 \mathrm{kN}$ or equal to $875300 \mathrm{~N}$. Then the result of force lift that has been found before can be calculated percentage of contribution to the value of ship resistance with the following formula :

$$
\frac{\text { Force Lift }}{\text { Resistance of ship }} x 100 \%
$$

The above formula is used for each vessel speed of 10 , $11,12,13,14,15$, and 16,2 knots.

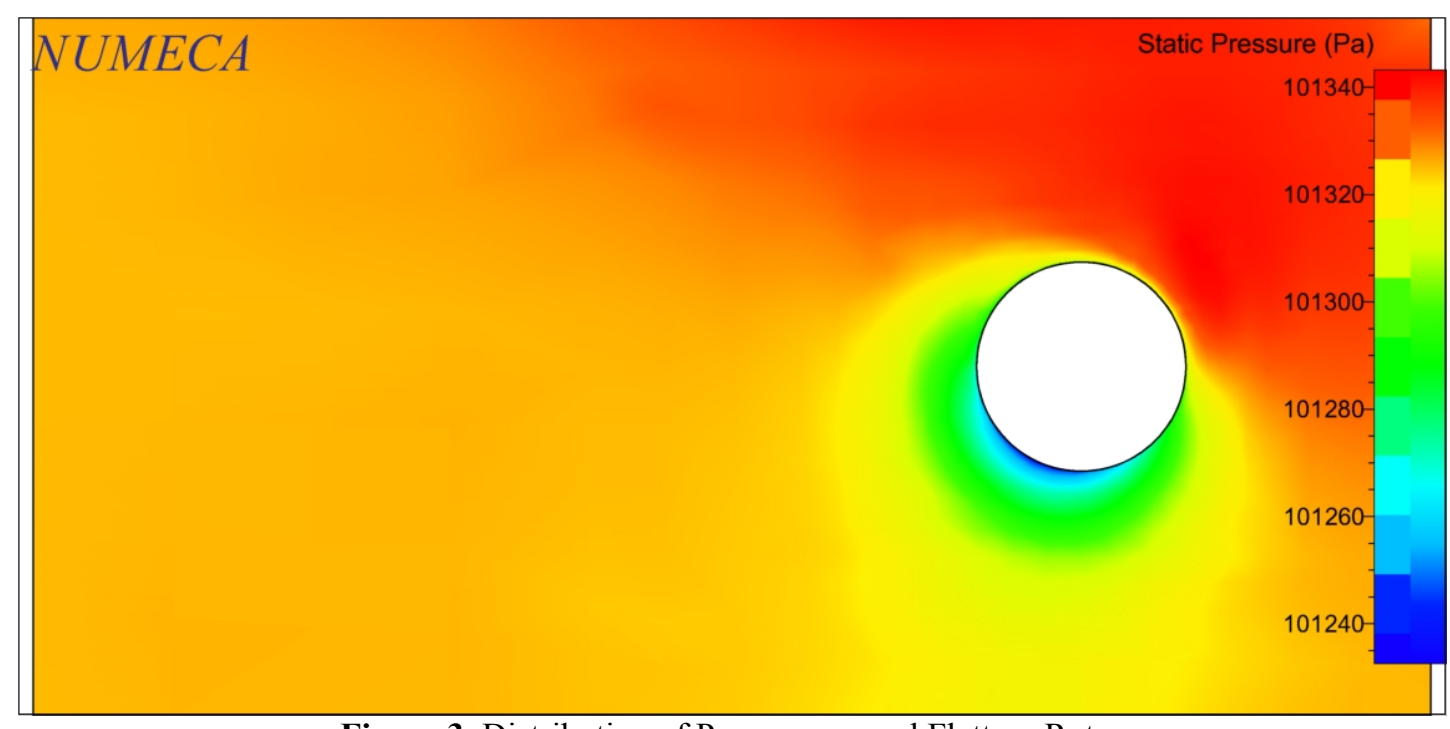

Figure 3. Distribution of Pressure around Flettner Rotor 


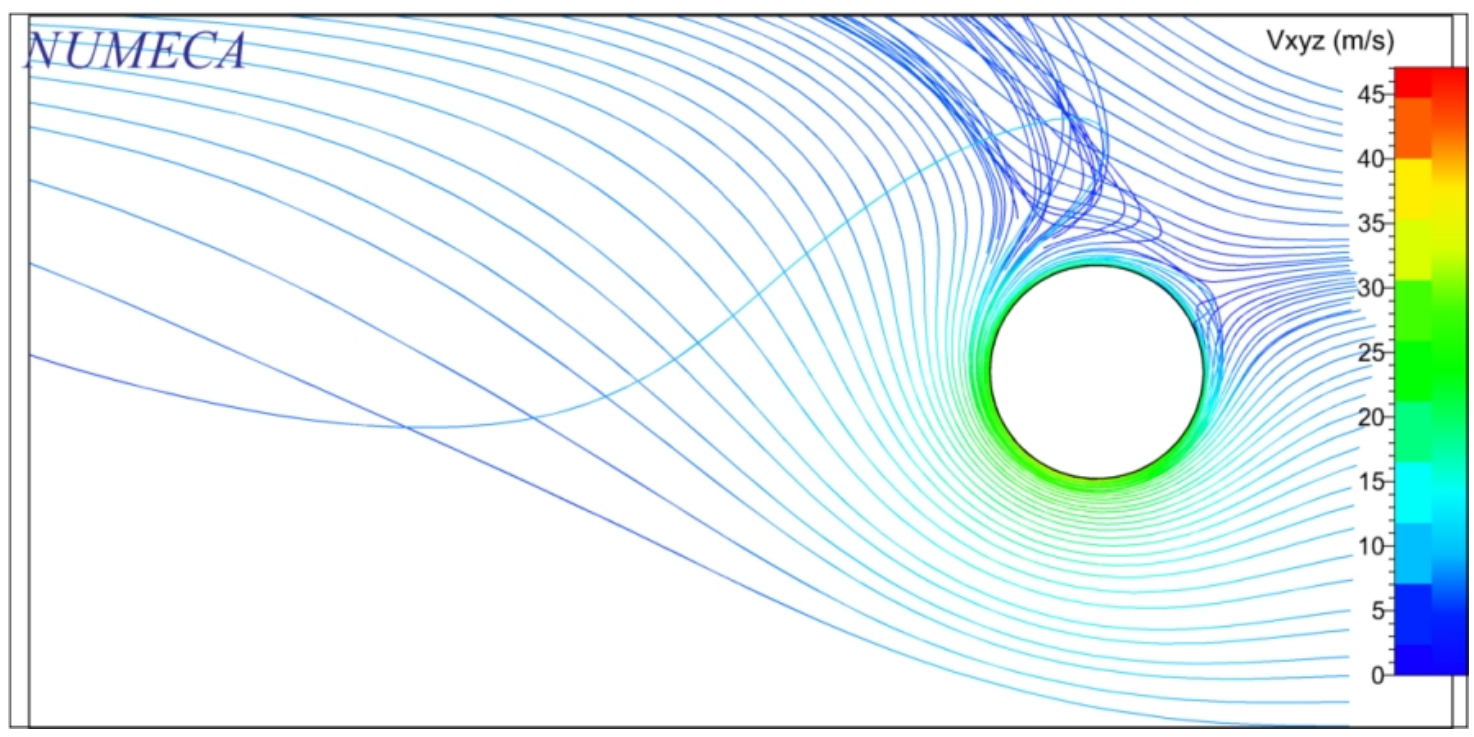

Figure 4. Wind Flow around Flettner Rotor

\section{RESULT AND DISCUSSION}

The results of The Numeca software can be viewed by selecting the CFView menu. The following example shows the results of the flettner rotor with rotation 300 rpm and wind speed 5 knot simulation using numeca software, see figure 3-4.

To see the distribution of pressure occurring around the fluid can select the static pressure menu in the quantities dialog box. In the picture shows that there is a large pressure difference between the two sides of the rotor flettner. Where the reddish color signifies high pressure while the blue color tends to be the opposite.

From the whole simulation performed the pressure distribution that happened tend to same. Because on the whole simulation effect magnus work. Therefore, in order to better know the difference in pressure that occurs with each other, then the legend for all simulation results is equalized based on the highest pressure difference.

Based on Bernoulli's law the value of pressure will be inversely proportional to the value of velocity. So if we take the picture the distribution of the fluid velocity around the flettner rotor will be seen in contrast to the image at the pressure distribution.

Then after that calculated the value of cl by using the above formula. Here are the results of coefficient lift values in the form of tables 2 and figure 5.

TABLE 2.

COEFFICIENT LIFT

\begin{tabular}{ccccc}
\hline No. & RPM Rotor & $\begin{array}{c}\text { Wind Speed } \\
(\text { knot })\end{array}$ & $\begin{array}{c}\text { Force } \\
\text { Lift }(\mathrm{N})\end{array}$ & Coefficient Lift \\
\hline 1 & 0 & 5 & 6,78 & 0,01 \\
2 & 0 & 10 & 283,17 & 0,43 \\
3 & 0 & 15 & 2187,32 & 3,32 \\
4 & 0 & 20 & 3318,29 & 5,04 \\
5 & 100 & 5 & 4340,74 & 6,60 \\
6 & 100 & 10 & 10219,38 & 15,53 \\
7 & 100 & 15 & 18317,57 & 27,84 \\
8 & 100 & 20 & 24196,21 & 36,77 \\
9 & 300 & 5 & 4227,13 & 6,42 \\
10 & 300 & 10 & 13844,57 & 21,04 \\
11 & 300 & 15 & 25635,78 & 38,96 \\
12 & 300 & 20 & 56190,49 & 85,39 \\
13 & 500 & 5 & 5375,05 & 8,17 \\
14 & 500 & 10 & 16591,45 & 25,21 \\
15 & 500 & 15 & 31621,24 & 48,06 \\
\hline
\end{tabular}




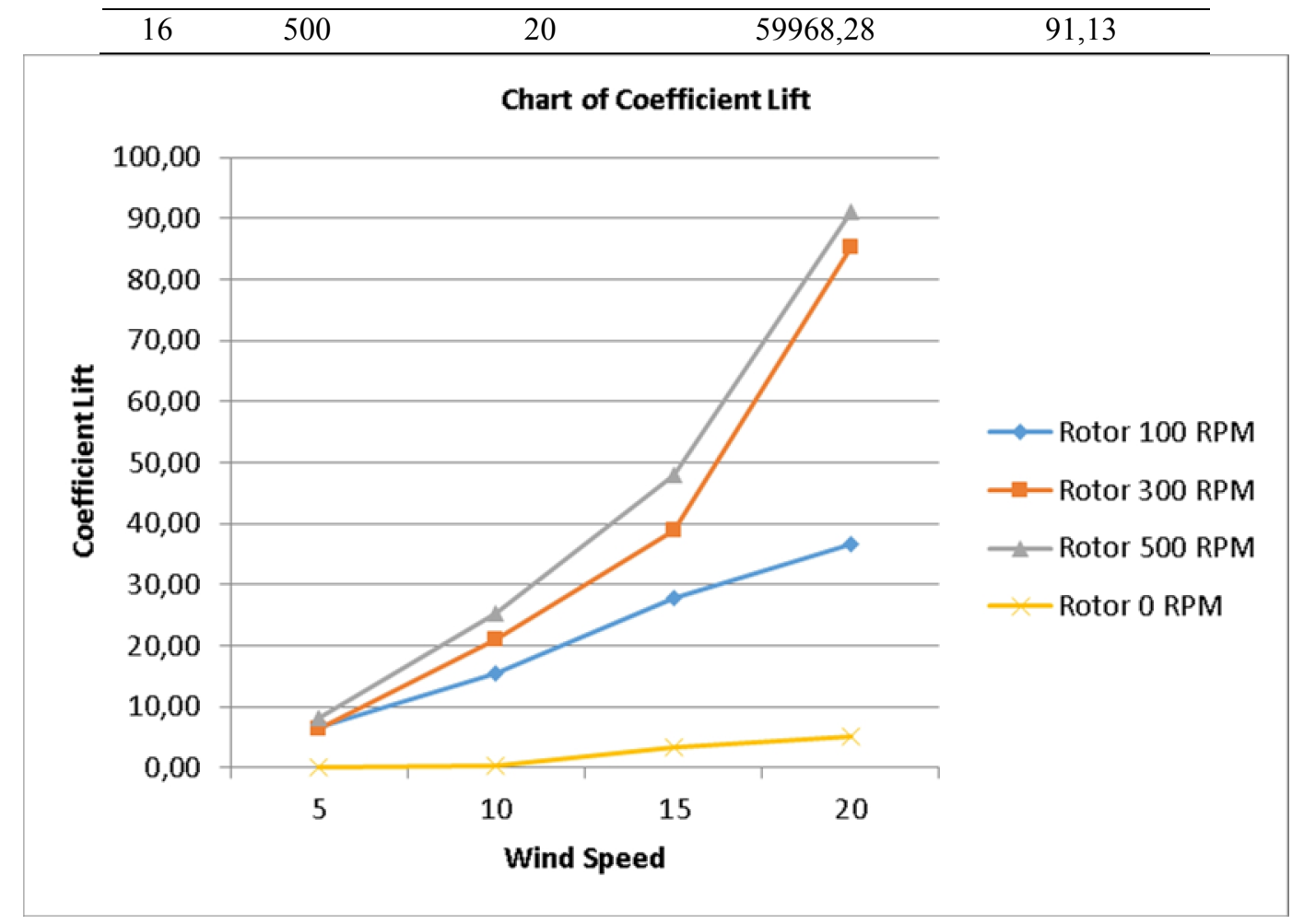

Figure 5. Chart of Coefficient lift

TABLE 3.

CONTRIBUTION OF FLETTNER Rotor IN EFFECTIVE ANGLE

\begin{tabular}{cccccccc}
\hline \multirow{2}{*}{ No. } & Coefficient & \multicolumn{7}{c}{ Speed of Vessel } \\
\cline { 3 - 8 } & Lift & 10 knot & 11,08 knot & 12,17 knot & 13,1 knot & 14,18 knot & 16,2 knot \\
\hline 1 & 6,6 & $1,262 \%$ & $1,052 \%$ & $0,890 \%$ & $0,777 \%$ & $0,665 \%$ & $0,496 \%$ \\
2 & 15,53 & $2,972 \%$ & $2,477 \%$ & $2,096 \%$ & $1,829 \%$ & $1,566 \%$ & $1,168 \%$ \\
3 & 27,84 & $5,326 \%$ & $4,441 \%$ & $3,757 \%$ & $3,278 \%$ & $2,808 \%$ & $2,093 \%$ \\
4 & 36,77 & $7,036 \%$ & $5,866 \%$ & $4,963 \%$ & $4,330 \%$ & $3,709 \%$ & $2,764 \%$ \\
5 & 6,42 & $1,229 \%$ & $1,025 \%$ & $0,867 \%$ & $0,756 \%$ & $0,648 \%$ & $0,483 \%$ \\
6 & 21,04 & $4,026 \%$ & $3,356 \%$ & $2,840 \%$ & $2,478 \%$ & $2,122 \%$ & $1,582 \%$ \\
7 & 38,96 & $7,454 \%$ & $6,215 \%$ & $5,259 \%$ & $4,588 \%$ & $3,929 \%$ & $2,929 \%$ \\
8 & 85,39 & $16,339 \%$ & $13,622 \%$ & $11,526 \%$ & $10,056 \%$ & $8,613 \%$ & $6,420 \%$ \\
9 & 8,17 & $1,563 \%$ & $1,303 \%$ & $1,103 \%$ & $0,962 \%$ & $0,824 \%$ & $0,614 \%$ \\
10 & 25,21 & $4,824 \%$ & $4,022 \%$ & $3,403 \%$ & $2,969 \%$ & $2,543 \%$ & $1,896 \%$ \\
11 & 48,06 & $9,195 \%$ & $7,666 \%$ & $6,486 \%$ & $5,659 \%$ & $4,847 \%$ & $3,613 \%$ \\
12 & 91,13 & $17,438 \%$ & $14,538 \%$ & $12,301 \%$ & $10,732 \%$ & $9,192 \%$ & $6,851 \%$ \\
\hline
\end{tabular}

Based on the value of the coefficient lift, then the flettner rotor contribution is sought in percent. The table above shows the percentage contribution of the thrust force of the flettner rotor to the vessel with 6 variations of speed $(10,11.08,12.17,13.1,14.18$, and 16.2 knots) . The lift coefficient is taken only on the rotating flettner rotor. In the silent flettner rotor or $0 \mathrm{rpm}$ is not taken its contribution value because it does not produce additional thrust force on the vessel, see table 3 .

\section{CONCLUSION}

Example of $4000 \mathrm{dwt}$ container ships taken is "Sakura". Which has dimensions Lwl x B x D is $103.9 \times 17.8 \times 8.5$ and the assumption of coefficient block is

0.7. Design of flettner rotor for 4000 DWT container vessel has $18 \mathrm{~m}$ high dimension with $3 \mathrm{~m}$ diameter.

The ratio between the rotor flettner's RPM and the fluid velocity is directly proportional to the resulting thrust. So the greater the RPM of the flettner rotor the greater the 
force produced. as well as the wind speed, the greater the wind speed, the greater the force produced.

The largest coefficient lift value is obtained when the flettner rotor is used at $500 \mathrm{rpm}$ at wind speed 20 knots is 91.13. Then the lowest value of $\mathrm{cl}$ is on the flettner rotor with a speed of $300 \mathrm{rpm}$ at a wind speed of 5 knots is 6.42 .

The flettner rotors contribution to the highest velocity of the vessel is on the flettner rotor with $500 \mathrm{rpm}$ flettner rotor rotation at wind speed 20 knots on a vessel with a 10 knot velocity is $17.438 \%$. While the smallest contribution is on the flettner rotor with $100 \mathrm{rpm}$ rotation at wind speed 5 knots on the ship with a speed of 16.2 knots that is $0.483 \%$.

\section{REFERENCES}

[1] T Michael, et al, "Propulsive Power Contribution of a Kite and a Flettner Rotor on Selected Shipping Routes", University of Manchester, United Kingdom, 2014.

[2] J Seifert, "A Review of The Magnus Effect in Aeronautics", Germany, 2012.

[3] S Ali, et al, "Aerodynamic Performance of a Circulating Airfoil Section for Magnus Systems via Numerical Simulation and Flow Visualization", Isfahan University of Technology, Iran, 2016.

[4] P Ondra, "Analisa Aplikasi Flettner Rotor Pada Offshore Support Vessel Panjang 56 Meter Dengan Metode CFD”, Institut Teknologi Sepuluh Nopember, Surabaya, 2015.

[5] B Fandy, "Analisa Aplikasi Turbin Kobold Blade Kembar Sebagai Pembangkit Listrik Tenaga Arus Laut Dalam Di Bangunan Lepas Pantai”, Institut Teknologi Sepuluh Nopember, Surabaya, 2015.

[6] S Ahmad, et al, "Computational Study on Novel Circulating Aerofoils for Use in Magnus Wind Turbine Blades", Isfahan University of Technology, Islamic Republic of Iran, 2015.

[7] C Tim, et al, "Back to The Future? A Re-examination of The aerodynamics of Flettner-Thom Rotors for Maritime Propulsion", 2013.

[8] J Craft, et al, "Dynamic Performance of Flettner Rotors with and Without Thom Discs", University of Manchester, Manchester,
United Kingdom. 